\title{
Effect of food deprivation on neuropeptide $Y$ immunoreactivity and concurrent biochemical and gonadal responses in tilapia Oreochromis mossambicus (Peters, 1852)
}

\author{
VIJAYALAXMI, BHAGYASHREE SHYAMANNAVAR, SUPRIYA PATIL, N. P. KHAJI \\ AND C. B. GANESH \\ Department of Studies in Zoology, Karnatak University, Dharwad - 580 003, Karnataka, India \\ e-mail: ganeshkcd@gmail.com
}

\begin{abstract}
The effect of short and long term fasting on neuropeptide Y (NPY) secreting neurons in the brain and concurrent biochemical and gonadal responses were determined in the cichlid fish Oreochromis mossambicus (Peters, 1852). Exposure of fish to fasting for 6 or 12 days resulted in intensely stained NPY-immunoreactive neurons in the nucleus entopeduncularis and the nucleus preopticus regions of the brain in contrast to moderately stained neurons in control fishes, whereas food supplementation after 6 days starvation restored NPY-immunoreactive profile to the same state as in control groups in both male and female fish. Gonadosomatic index (GSI) remained significantly lower in female fishes subjected to fasting alone as well as fasting followed by refeedings compared to controls. While the hepatosomatic index (HSI) also showed a significant decrease in fasting male and female fish compared to controls, it increased subsequently in fishes exposed to refeeding after starvation. In addition, a significant decrease in the serum levels of glucose and triglycerides as well as the hepatic tissue protein content in fasting fish compared to those of controls in both sexes suggested gluconeogenesis. Although the serum levels of glucose and triglycerides were reinstated in both male and female fishes subjected to starvation and refeeding., the hepatic tissue protein levels were not completely restored in females. Collectively, these results suggest that fooddeprivation, either for short or long term duration, significantly increases the secretory activity of NPY neurons in the brain concomitant with a significant decrease in the serum levels of glucose and triglycerides, the hepatic tissue protein content and the GSI in both sexes. Although males recovered from the effects of starvation following refeeding, females appeared to be more vulnerable to the effects of fasting.
\end{abstract}

Keywords: Fasting, Food intake, Neuropeptide Y, Refeeding, Starvation

\section{Introduction}

The feeding behaviour of animals is complex and the acts of feeding and ingestion are the final results of a number of factors between the animal and its ecological interactions (Sundstrom et al., 2016). Neuropeptide $\mathrm{Y}$ (NPY), a 36 amino acid peptide, is one of the most conserved neuroendocrine peptides (Larhammar, 1996) and is known to be involved in the regulation of feeding behaviour in mammals (Schwartz et al., 1993; Stanley, 1993; Kaiyala et al., 1995), amphibians (Crespi et al., 2004) as well as in fish (Subhedar, 2006; Volkoff, 2016; Yan et al., 2017). However, more comparative studies in different animals with varying life histories are needed for the understanding of evolution of regulation of energy balance in vertebrates (Crespi et al., 2004). Neuropeptide $\mathrm{Y}$ significantly increases food intake and growth rate in the Nile tilapia Oreochromis niloticus (Kiris et al., 2007), the estuarine cod Epinephelus coioides and the olive flounder Paralichthys olivaceus (Wu et al., 2012; Li et al., 2017). Neuropeptide Y levels are increased following exposure to food deficiency in the goldfish Carassius auratus (Lopez-Patino et al., 1999). Severe disturbances observed in daily food intake in the chinook salmon Oncorhynchus tshawytscha as well as in coho salmon Oncorhynchus kisutch, leading to suppression of plasma levels of insulin and glucose, concomitant with an increase in NPY gene expression (Silverstein et al., 1998). Similarly, restriction in daily food ration intake for one week or food-deprivation for $72 \mathrm{~h}$ increased the brain NPY mRNA levels in the goldfish C. auratus (Narnaware et al., 2000); however, increased NPY mRNA levels in brain are restored following refeeding for 1-3 h (Narnaware and Peter, 2001). Although the above studies have suggested the involvement of NPY in energy balance and food intake in fish, duration dependent effects of short and long term food deprivation on NPY and gonadal responses in fish are not clear. It is also not clear whether NPY secretory activity is dependent on energy status and gender of the animal. The present study aimed to determine the response of NPY secreting cells in the brain and corresponding alterations in the serum levels of glucose, triglycerides and 
hepatic protein levels as well as the response of gonads in male and female $O$. mossambicus exposed to short- and long-term fasting conditions. The study also investigated changes if any in these parameters after refeeding in starved $O$. mossambicus.

\section{Materials and methods}

\section{Experimental animals}

Healthy specimens of $O$. mossambicus weighing 25-30 g collected from ponds in and around Dharwad District $\left(75^{\circ} 01^{\prime} \mathrm{E} ; 15^{\circ} 27^{\prime} \mathrm{N}\right)$ were brought to the laboratory and reared in freshwater aquaria (size, $36^{\prime \prime} \times 1 " \times 1 "$; $\mathrm{L} \times \mathrm{W} \times \mathrm{H}$ ) under natural photoperiod. The fish were acclimatised to laboratory rearing conditions for two months before the commencement of the experiment. While the males were continuous breeders, the females were assessed (by stripping of mouthbrooding females) to be in previtellogenic phase during the experiment. (Ganesh, 2014). An aerator was fitted to each aquarium and the water was re-circulated daily to avoid algal growth and accumulation of plankton.

\section{Experimental design}

The experimental set up included six groups for both male $(n=30)$ and female fish $(n=30)$ separately. The first group of fish ( $\mathrm{n}=5$ for each sex) sampled on the day of initiation of experiment were considered as initial controls. From the remaining stock, 25 female and 25 male fishes were segregated at a stocking density of five fish per aquaria and designated as the experimental groups 2-6. The fish in second and third groups were fed with food pellets (Taiyo grow, Chennai)@3 g per aquaria and sacrificed on days 6 and 12, whereas those in fourth and fifth groups were subjected to starvation and sacrificed on days 6 and 12 respectively and served as fed control groups. The fish in the sixth group were also subjected to starvation up to day 6 , but fed afterwards with same quantity of food as in controls, until they were sacrificed on day 12. At each autopsy, weights of the body, the ovary, the testis and the liver were recorded to calculate the gonadosomatic index (GSI $=100 \times$ Gonad weight/Body weight) and the hepatosomatic index (HSI $=100 \times$ Liver weight/Body weight). The experiments were carried out in accordance with Institutional Animal Ethical guidelines.

\section{Biochemical assays}

Blood samples were collected from the caudal vein; the serum was separated and centrifuged at $3000 \mathrm{rpm}$ for $10 \mathrm{~min}$. Serum was stored at $-20^{\circ} \mathrm{C}$ until biochemical estimations were carried out. The serum glucose concentration was measured as per the method described by Trinder (1969a) and the serum concentrations of triglyceride were estimated as per Trinder (1969b). Fresh liver tissue was frozen, thawed and homogenised for the determination of total protein content by Bradford method (Bradford, 1976).

\section{Immunocytochemistry}

The fish were anaesthetised using 2-phenoxyethanol (Sigma-Aldrich, USA) and perfused transcardially with 20 $\mathrm{ml}$ of ice-cold phosphate buffered saline (PBS, pH 7.4) and then with $20 \mathrm{ml}$ of ice-cold Bouin's fluid. The brains were dissected out and again fixed in the Bouin's fluid overnight. The tissues were rinsed in PBS and cryoprotected in icecold 10\% (2h), 20\% (2h), and 30\% (overnight) sucrose solution. Sagittal as well as transverse frozen sections were cut at $16 \mu \mathrm{m}$ thickness using a cryomicrotome (Leica CM1510S, Germany). For immunocytochemical localisation, streptavidin-biotin-peroxidase method (Gaikwad et al., 2003) was used to label NPY-secreting cells in the brain. The sections were rinsed in PBS for 15 min, followed by $2 \%$ bovine serum albumin (BSA) in PBS containing $0.3 \%$ Triton $\mathrm{X}-100$. The sections were then incubated overnight at $4^{\circ} \mathrm{C}$ in humid atmosphere with polyclonal antibody against the human NPY produced in rabbit (1:4000; Immunostar, USA) in PBS containing $0.3 \%$ Triton X-100 and $2 \%$ BSA. The sections were rinsed in PBS for $10 \mathrm{~min}$. and incubated for $2 \mathrm{~h}$ with biotinylated goat antirabbit IgG (1:100; Sigma, USA) followed by streptavidin peroxidase (Sigma-Aldrich, EXTRA-3 kit) for $1 \mathrm{~h}$. The antigen-antibody complex was visualised in the form of reddish brown precipitate following staining wth Amino-9-ethyl carbazole (Sigma-Aldrich, USA) for 5-7 min. Finally, the sections were rinsed in distilled water and then mounted with glycerol-gelatin. Control procedures for the specificity of the antibodies included: a) exclusion of primary antibody, b) substitution of primary antisera with $1 \%$ BSA and buffer, c) omission of secondary antibody and d) preabsorption of diluted antisera $(1 \mu 1$ antibody in $200 \mu$ l buffer) with $1 \mu \mathrm{g}$ NPY peptide $24 \mathrm{~h}$ prior to incubation. No immunoreactivity was observed following these control procedures, confirming the specificity of the antisera. The immunoreactivity was measured using image analysis system that consisted of BX 41 microscope attached with E-330 camera (Olympus, Japan) and evaluated using image J software version 1.45 (NIH, Bethesda, MD, USA). The pixel intensities were measured in both non-immunoreactive background and immunoreactive cells. The threshold pixel intensity of the background was subtracted from the total intensity. The threshold intensity of NPY-immunoreactive cells was measured in five sections of each fish brain $(n=5)$ and expressed as integrated units (mean $\pm \mathrm{SE}$ ).

\section{Statistical analysis}

The mean values of different parameters among the experimental groups for males or females were analysed 
by employing one-way ANOVA and Student-NewmanKeuls multiple comparison post-hoc test using SigmaStat 3.5 software. The differences in various parameters between male and female fish were determined by Student $t$-test. The differences for all comparisons were considered significant at $\mathrm{p}<0.05$ level.

\section{Results}

In this study, application of immunocytochemical technique revealed the distribution of NPY immunoreactive cells in the nucleus entopeduncularis (NE) and the nucleus preopticus (NPO) regions of the brain of O. mossambicus. The pattern of NPY immunoreactivity in the brain did not differ significantly between male and female fish. While NPY-immunoreactive cell population was numerous and moderately stained in the NE (Fig. 1a; $28.86 \pm 2.2$ ), only few moderately stained cells were observed in the NPO region (Fig. 1d; $33.13 \pm 0.92$ ) in initial controls as well as in fed control fishes sacrificed on days 6 and 12. However, the brain of fishes exposed to starvation showed significantly $(p<0.05)$ higher intense staining in NPY neurons of the NE (Fig. 1b; 77.26 1.72 ) as well as the NPO (Fig. 1e; $78.60 \pm 1.15$ ) regions on days 6 and 12 indicating increased secretory activity of these cells compared to those of initial controls and fed controls on days 6 and 12. In fish subjected to starvation for 6 days followed by refeeding upto 12 days, the intensity of NPY-immunoreactivity was significantly $(\mathrm{p}<0.05)$ lower compared to the fish exposed to fasting alone and resembled that of controls in both the NE (Fig. 1c; 27.00 \pm 1.02 ) and the NPO (Fig. 1c; $37.17 \pm 0.96)$ regions of the brain.

Although the mean GSI did not vary significantly among initial controls, fed controls (on days 6 and 12) and fasting fish on day 6; a significant $(\mathrm{p}<0.05)$ decrease was observed in fasting fish on day 12 compared to controls (Fig. 2a). However, the mean GSI in starved and refed group also remained significantly $(p<0.05)$ lower compared to those of initial controls and fed controls. While the GSI did not show any significant difference among males of different experimental groups, it remained significantly $(p<0.05)$ lower in all experimental groups except for fasting fish on day 12 compared to those of female fish (Fig. 2a). The HSI in female fish did not show statistically significant difference among initial controls and fed controls on day 6 or 12 , but decreased significantly $(\mathrm{p}<0.05)$ in fasting fish on days 6 and 12 (Fig. 2b). However, refeeding in starved fish resulted in significantly $(p<0.05)$ higher HSI compared to fishes subjected to fasting alone (Fig. 2b). Similar trend was also noticed in male fish (Fig. 2b).

No significant difference was noticed in serum levels of glucose and triglyceride and hepatic tissue protein concentration among initial controls and fed controls on day 6 or 12 in both male and female fish (Fig. 3A-C). A significant $(\mathrm{p}<0.05)$ decrease in serum glucose levels was found both in fasting males and females on days 6 and 12 compared to controls (Fig. 3a). The serum glucose levels in starved and refed group increased significantly $(\mathrm{p}<0.05)$ compared to fasting males as well as females on day 6 and 12 , and remained almost same compared to that of initial controls and fed controls on day 6 and 12 (Fig. 3a).

A significant $(p<0.05)$ decrease in liver tissue protein concentration was found in fasting females on day 6 or 12 compared to those of initial controls and fed controls on day 6 and 12 (Fig. 3b). Significant $(p<0.05)$ decrease in the liver tissue protein concentration occurred in fasting male fish on day 6 compared to those of controls, and a further significant $(\mathrm{p}<0.05)$ decrease was noticed in fasting fish on day 12 compared to fasting fish on day 6 and initial controls as well as fed controls on day 6 and 12 (Fig. 3b). Feeding of starved fish resulted in significantly $(p<0.05)$

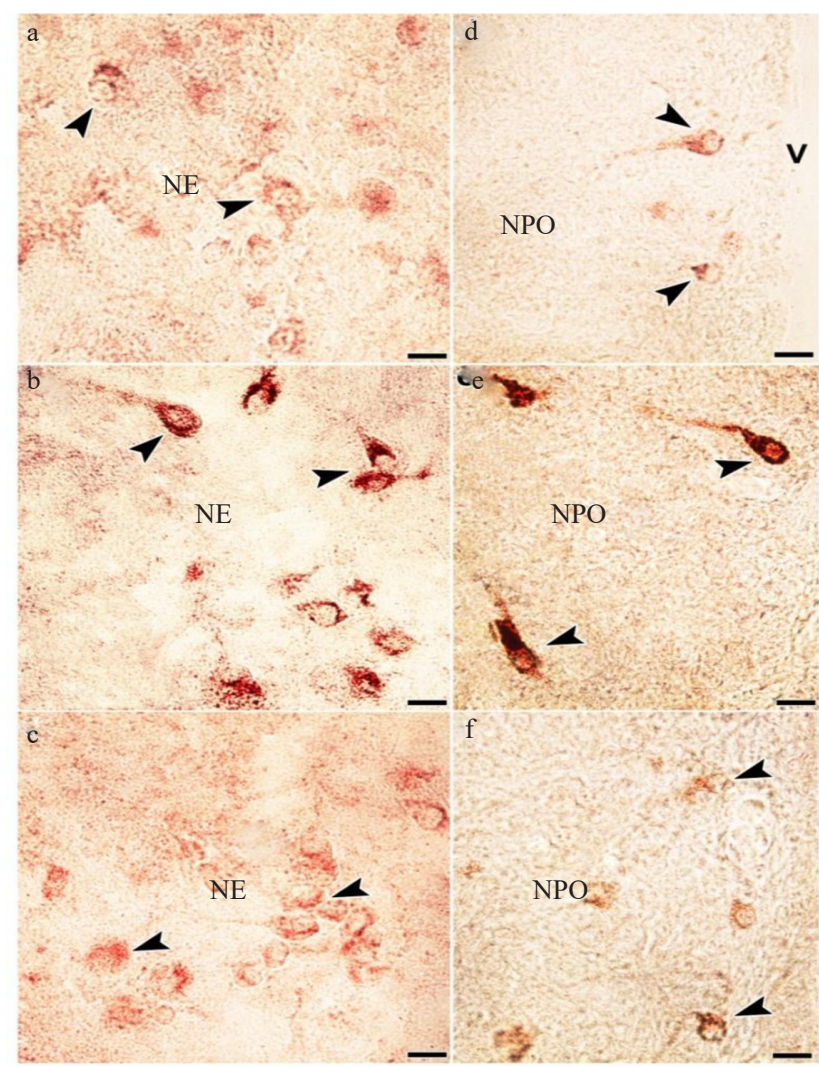

Fig. 1. Transverse sections of the brain through NE and NPO regions showing NPY-immunoreactive cells in different experimental groups. Note the moderate immunostaining in initial control and fed control fish on day 6 and 12 (a and d), intensely stained cells in fish exposed to fasting for 6 and 12 days ( $b$ and e). NPY-immunoreactive cells in fishes subjected to starvation followed by refeeding (c and f) is similar to that of initial control and fed control fish ( Scale bar $=25 \mu \mathrm{m})$ 
higher levels of liver tissue protein concentration in males, but not in females as compared to fasting fish on day 6 and 12 (Fig. 3b).

The serum triglyceride level in fasting females on day 6 although found lower, did not differ significantly from that of initial controls and fed controls on day 6 and 12 , whereas a significant $(\mathrm{p}<0.05)$ decrease was noticed in fasting females on day 12 compared to fasting fish on day 6 as well as initial controls and fed controls on day 6 and 12 (Fig. 3c). In contrast, significantly $(\mathrm{p}<0.05)$ lower levels of serum triglycerides were noticed in fasting males on day 6 compared to those of initial controls and fed controls on day 6 or 12, but these levels increased later in fasting fish on day 12 (Fig. 3c). Food supplementation to fish subjected to starvation followed by refeeding, restored the serum triglyceride levels significantly, compared to fasting females on day 12 and male fish on day 6 (Fig. 3c). The serum triglyceride levels were significantly $(\mathrm{p}<0.05)$
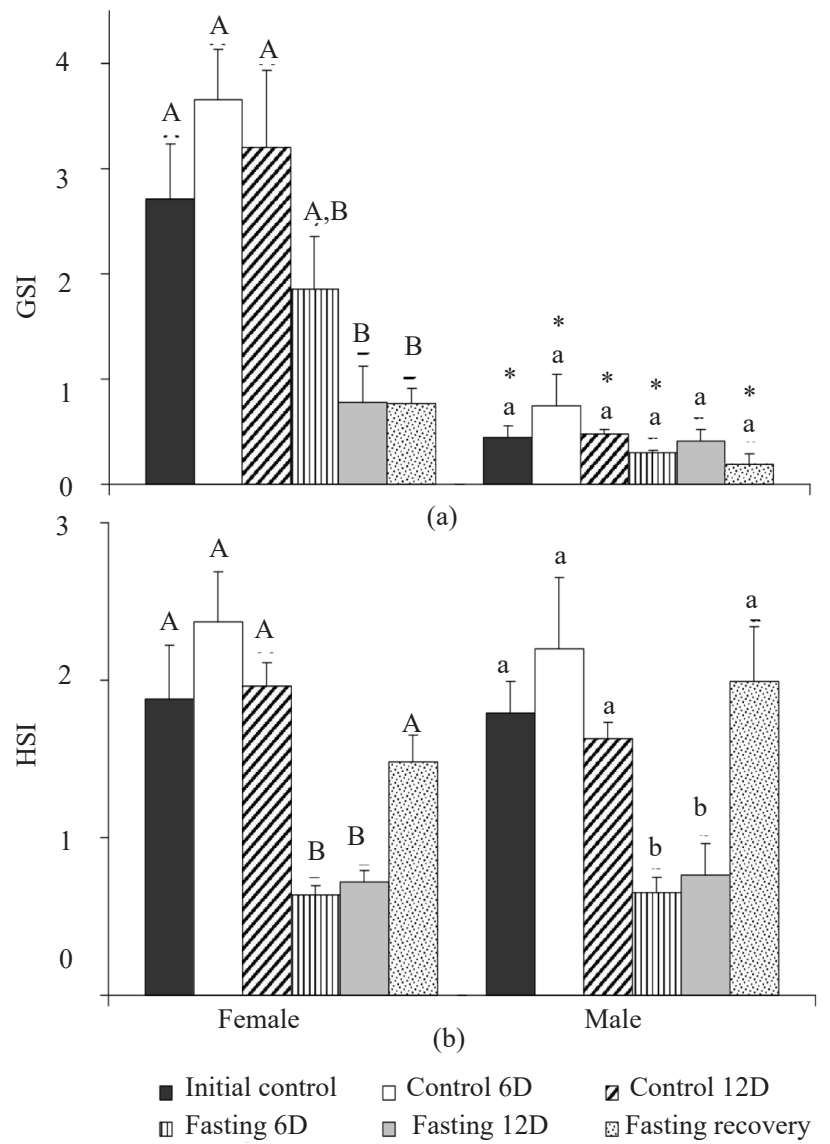

Fig. 2. Effect of food deprivation on (a) GSI and (b) HSI in O. mossambicus. Groups with similar superscripts (upper case letters for females, and lower case letters for males) are not significantly different from each other, whereas different superscripts indicate significant $(\mathrm{p}<0.05)$ difference. *Significant $(\mathrm{p}<0.05)$ difference between males and females (Student $t$ test). Values are means \pm SE. lower in initial controls as well as fed controls on day 6 and 12 and fasting males on day 6 compared to fasting females (Fig. 3c).

\section{Discussion}

Although exposure to food deprivation decreased NPY mRNA expression in the rainbow trout (Gong et al., 2016), majority of the studies have shown increased NPY activity following starvation. For instance, the
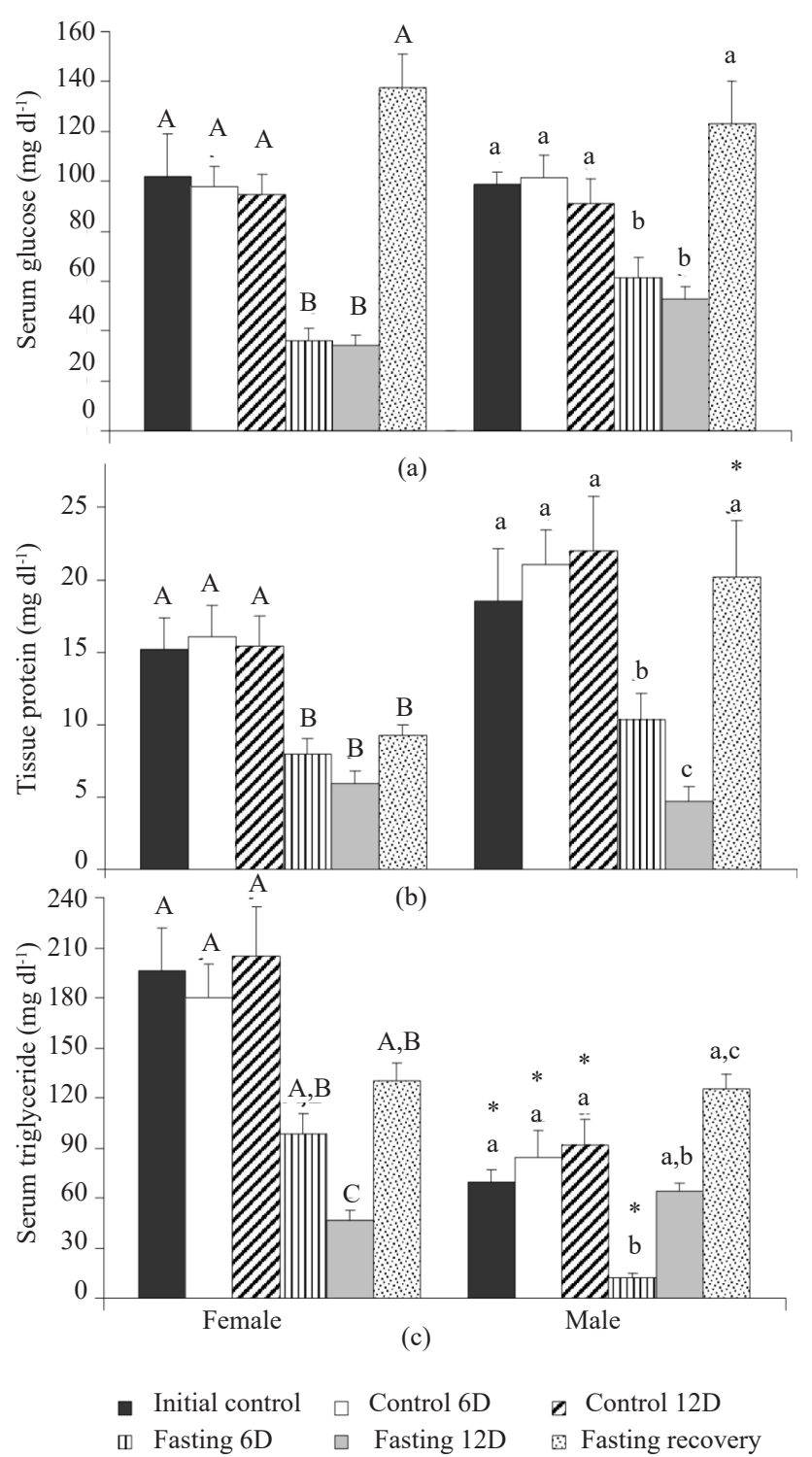

Fig. 3. Effect of food-deprivation on serum levels of (a) glucose, (b) triglycerides and (c) tissue protein levels in $O$. mossambicus. Groups with similar superscripts (upper case letters for females, and lower case letters for males) are not significantly different from each other, whereas different superscripts indicate significant $(\mathrm{p}<0.05)$ difference. ${ }^{*}$ Significant $(\mathrm{p}<0.05)$ difference between males and females (Student $t$ test). Values are means \pm SE. 
orexigenic function of NPY was shown by stimulatory effect of NPY treatment on food intake and growth rate in the Nile tilapia $O$. niloticus (Kiris et al., 2007), the estuarine cod E. coioides (Wu et al., 2012), and the olive flounder P. olivaceus (Li et al., 2017). The number of NPY immunoreactive neurons increased in the hypothalamus and the posterior tuberculum, following seven days fasting in the goldfish C. auratus (Yokobori et al., 2012), whereas NPY mRNA abundance decreased after meal in the Atlantic cod Gadus morhua (Kehoe and Volkoff, 2007), the zebrafish (Tian et al., 2015), and the grass carp (Zhou et al., 2013). Likewise, refeeding after starvation resulted in decreased NPY mRNA levels in the hypothalamus of the goldfish C. auratus (Narnaware and Peter, 2001).

The present study revealed the immunoreactivity of NPY secreting cells in the NE and NPO regions of the brain under short- and long-term food deprivation and post-starvation feeding conditions in both male and female O. mossambicus. Intensely stained NPY immunoreactive cells were observed in the brain of fish exposed to starvation for 6 and 12 days compared to that of controls, whereas no differences were noticed in the immunoreactivity of NPY neurons between short- and long-term food deprivation conditions. The moderate NPY-immunostaining in fishes subjected to refeeding subsequent to starvation, similar to that of controls clearly indicates that the secretory activity of these cells depends on the feeding status of the fish. Collectively these results suggest that the response of NPY secreting neurons is not dependent either on duration of starvation or on sex.

Involvement of NPY in the energy homeostasis and food intake has been suggested in fish as observed in mammals. Hypothalamic NPY neurons decrease their firing rate in response to increased levels of glucose in mammals (Levin et al., 2004). This process of glucosensing appears to occur in fishes also. For example, food restriction-induced suppression of plasma insulin and glucose levels has been shown to increase NPY mRNA levels in the chinook salmon $O$. tshawytscha and the coho salmon $O$. kisutch (Silverstein et al., 1998). The increased NPY mRNA abundance was decreased in the hypothalamus after either glucose treatment (OteroRodino et al., 2015) or feeding with a high carbohydrate diet (Narnaware and Peter, 2002) in C. auratus. The present study provides immunohistochemical evidence for the increased secretory activity of NPY neurons in the NE and the NPO regions of the brain, concomitant with a significant decrease in the serum glucose levels in both male and female fish exposed to starvation. Moreover, replenishment of the serum glucose levels in group subjected to refeeding after starvation, was concurrent with moderate NPY immunostaining, similar to that of initial controls and fed controls. Together, these results suggest the possibility of occurrence of glucosensing dependent NPY secretory activity in tilapia, as observed in mammals.

A general significant decrease in the serum triglyceride levels was noticed in male fish compared to those of females. This could be attributed to the occurrence of high fat reserve in females than in males. Robinson and Robinette (1994) noticed the presence of high visceral fat body content in females than in males among channel catfish Ictalurus punctatus. In the present study, the serum triglyceride levels in starving females (day 6) did not drop significantly, but decreased significantly in starving male fish on day 6 compared to those of controls. Although this could be attributed to high visceral fat reserve in females, and at a later point, significant decrease observed in serum triglyceride levels indicates the possibility of occurrence of gluconeogenesis followed by starvation. This contention is further supported by the fact that the serum levels of triglycerides were restored in fishes subjected to refeeding after starvation.

Dietary proteins are required to achieve maximum growth rates and amino acids often replace carbohydrates as precursors of energy metabolism in fish (Walton and Cowey, 1982). The liver was shown to respond to starvation, through proteolysis leading to rapid loss of proteins in mammals (Seglen and Bohley, 1992). In the present study, significantly lower hepatic protein levels observed in fish exposed to starvation for day 6 or 12 is indicative of absence of dietary proteins in both sexes. However, it is interesting to note that the hepatic protein levels were completely restored following refeeding after starvation, in males, but not in females. These results suggest an apparent difference in the response of males and females to starvation.

Stimulatory effect of NPY on gonadotrophic hormone $(\mathrm{GtH})$ under normal conditions is reported in the trout Oncorhynchus mykiss, the carp Cyprinus carpio (Breton et al., 1991), the goldfish (Peng et al., 1993), and the seabass Dicentrarchus labrax (Cerda-Reverter et al., 1999). In the present study, the alteration in NPY secretory activity was correlated with gonadal status of the fish. Although, the status of testicular activity cannot be generally assessed by GSI, significantly higher GSI in females is an index of presence of fully grown vitellogenic follicles in O. mossambicus (Chabbi and Ganesh, 2012, Ganesh, 2014). In the present study, a significant decrease in GSI recorded in fasting females on day 12 , but not on day 6 , compared to those of controls suggests that chronic, but not short term, exposure to fasting significantly affects gonadal activity at least in females. Furthermore, the observation that refeeding did not result in the reversal 
of suppressive effect of fasting on gonads in females indicates an irreversible inhibitory effect of starvation in females. Since the process of vitellogenesis demands high energy investment (Wallace and Selman, 1981), the suppression of ovarian development observed could be due to deficiency in the dietary energy in the starving females. Alternatively, this inhibition could be also due to negative effects of deficiency of energy on gonadotropin secretion as suggested by Kile et al. (1991) for mammals.

The present study reports a tight correlation between the food supply and the hypothalamic NPY neurons in male and female tilapia. The fact that refeeding after exposure to starvation replenishes the levels of glucose and triglycerides in both sexes, but the starvation induced suppression observed in tissue protein content and ovarian activity in females suggests gender specific effect of starvation. Therefore, exposure of female fish to starvation and refeeding cycles need to be avoided during aquaculture practices in order to ensure good health and successful reproduction in fish.

\section{Acknowledgements}

We are thankful to Dr. Amul J. Sakharkar, Department of Psychiatry, University of Illinois at Chicago, USA for the kind gift of antisera for NPY and Department of Zoology, Karnatak Science College and Karnatak University, Dharwad for support. Infrastructural facilities received through grants from SERB-DST, New Delhi are gratefully acknowledged.

\section{References}

Bradford, M. M. 1976. A rapid and sensitive method for the quantitation of microgram quantities of protein utilizing the principle of protein-dye binding. Analyt. Biochem., 72: 248-254.

Breton, B., Mikolajczyk, T., Popek, W., Bienarz, K. and Epler, P. 1991. Neuropeptide Y stimulates in vitro gonadotropin secretion in teleost fish. Gen. Comp. Endocrinol., 84: 277-283. https://doi.org/10.1016/00166480(91)90050-G.

Cerda-Reverter, J. M., Sorbera, L. A., Carrillo, M. and Zanuy, S. 1999. Energetic dependence of NPY induced LH secretion in a teleost fish (Dicentrarchus labrax). Am. J. Physiol., 277: 1627-1634. doi: 10.1152/ajpregu.1999.277.6.R1627.

Crespi, E. J., Vaudry, H. and Denver, R. J. 2004. Roles of corticotrophin-releasing factor, neuropeptide $\mathrm{Y}$ and corticosterone in the regulation of food intake in Xenopus laevis. J. Neuroendocrinol., 16: 279-288. DOI:10.1111/ j.0953-8194.2004.01168.x.

Chabbi, A. and Ganesh, C. B. 2012. Stress-induced inhibition of recruitment of ovarian follicles for vitellogenic growth and interruption of spawning cycle in the fish Oreochromis mossambicus. Fish. Physiol. Biochem., 38: 1521-1532. DOI: 101007/s10695-012-9643-z.
Gaikwad, A., Biju, K. C. and Subhedar, N. 2003. GnRH-LH secreting cells axis in the pituitary of the teleost Clarias batrachus responds to neuropeptide $\mathrm{Y}$ treatment: an immunocytochemical study. Gen. Comp. Endocrinol., 131: 126-133.

Ganesh, C. B. 2014. Follicular development status and profile of $17 \beta$ estradiol and cortisol levels during spawning cycle in Oreochromis mossambicus (Peters). Indian J. Fish., 61: 45-51. https://doi.org/10.1016/j.jobaz.2015.09.005.

Gong, N., Johansson, M. and Bjornsson, B. T. 2016. Impaired central leptin signaling and sensitivity in rainbow trout with high muscle adiposity. Gen. Comp. Endocrinol., 235: 48-56. DOI:10.1016/j.ygcen.2016.06.013.

Kaiyala, K. J., Woods, S. C. and Schwartz, M. W. 1995. New model for the regulation of energy balance and adiposity by the central nervous system. Am. J. Clin. Nutr., 62: 1123S-1134S. DOI:10.1093/ajen/62.5.1123S.

Kehoe, A. S. and Volkoff, H. 2007. Cloning and characterization of neuropeptide Y (NPY) and cocaine and amphetamine regulated transcript (CART) in Atlantic cod (Gadus morhua). Comp. Biochem. Physiol. A., 146: 451-461. DOI:10.1016/j.cbpa.2006.12.026.

Kile, J. P., Alexander, B. M., Moos, G. E., Allford, D. M. and Nett, T. M. 1991. Gonadotropin-releasing hormone overrides the negative effect of reduced dietary energy on gonadotropin synthesis and secretion in ewe. Endocrinology, 128: 843-849.

Kiris, G. A., Kumlu, M. and Dikel, S. 2007. Stimulatory effects of neuropeptide $\mathrm{Y}$ on food intake and growth of Oreochromis niloticus. Aquaculture, 264: 383-389. https:// doi.org/10.1016/j.aquaculture.2006.12.004.

Larhammar, D. 1996. Evolution of neuropeptide Y, peptide YY and pancreatic polypeptide. Regul. Pep., 62: 1-11.

Levin, B. E., Routh, V. H., Kang, L., Sanders, N. M. and DunnMeynell, A. A. 2004. Neuronal glucosensing. What do we know after 50 years? Diabetes, 53: 2521-2528. https://doi. $\operatorname{org} / 10.2337 /$ diabetes.53.10.2521.

Li, M., Tan, X., Sui, Y., Jiao, S., Wu, Z., Wang, L. and You, F. 2017. The stimulatory effect of neuropeptide $Y$ on growth hormone expression, food intake and growth in olive flounder (Paralichthys olivaceus). Fish. Physiol. Biochem., 43: 11-18. doi: 10.1007/s10695-016-0263-x.

Lopez-Patino, M. A, Guijarro, A. I., Isorna, E., Delgado, M. J., Alonso-Bedate, M. and De Pedro, N. 1999. Neuropeptide $\mathrm{Y}$ has a stimulatory action on feeding behaviour in goldfish (Carrassius auratus). Eur. J. Pharmacol., 377: 147-153.

Narnaware, Y. K., Peyon, P. P., Lin, X. and Peter, R. E. 2000. Regulation of food intake by neuropeptide $\mathrm{Y}$ in goldfish. Am. J. Physiol. Regul. Integr. Comp. Physiol., 279: RI 025RI 034. https://doi.org/10.1152/ajpregu.2000.279.3.R1025.

Narnaware, Y. K. and Peter, R. E. 2001. Effects of food deprivation and refeeding on neuropeptide Y (NPY) mRNA levels in goldfish. Comp. Biochem. Physiol. B. Biochem. 
Mol. Biol., 129: 633-637. https://doi.org/10.1016/S10964959(01)00359-1.

Narnaware, Y. K. and Peter, R. E. 2002. Influence of diet composition on food intake and neuropeptide Y (NPY) gene expression in goldfish brain. Regul. Pept., 103: 75-83. https://doi.org/10.1016/S0167-0115(01)00342-1.

Otero-Rodino, C., Libran-Perez, M., Velasco, C., Lopez-Patino, M. A., Miguez, J. M. and Soengas, J. L. 2015. Evidence for the presence of glucosensor mechanisms not dependent on glucokinase in hypothalamus and hindbrain of rainbow trout (Oncorhynchus mykiss). PLoS ONE., 10:e0128603. DOI: 10.1371/journal.pone.0128603.

Peng, C., Trudean, V. L. and Peter, R. E., 1993. Seasonal variation of neuropeptide $\mathrm{Y}$ actions on growth hormone and gonadotropin-II secretion in the goldfish: effect of sex steroids. J. Neuroendocrinol., 5: 273-280.

Robinson, E. H. and Robinette, H. R. 1994. Effects of dietary protein level and feeding regimen on growth and on fattiness of channel catfish (Ictalurus punctatus). J. Appl. Aquac., 3: 6790. https://doi.org/10.1111/j.1749-7345.1999.tb00681.x.

Schwartz, M. W., Figlewicz. D. P., Woods, S. C., Porte, D. and Baskin, D. G. 1993. Insulin, neuropeptide Y and food intake. Ann. NY. Acad. Sci., 692: 60-71. https://doi. org/10.1111/j.1749-6632.1993.tb26206.x.

Seglen, P. O. and Bohley, P. 1992. Autophagy and other vacuolar protein degradation mechanisms. Experientia, 48: 158-172.

Silverstein, J., Breninger, T. J., Baskin, D. G. and Plisetskaya, E. M. 1998. Neuropeptide Y-like expression in the salmon brain increases with fasting. Gen. Comp. Endocrinol., 110: 157-165.

Stanley, B. G. 1993. Neuropeptide Y in multiple hypothalamic sites controls eating behaviour, endocrine and autonomic systems for body energy balance. In: Colmers, W. F. and Wahlestedt, C. (Eds.), The biology of neuropeptide $Y$ and related peptides, Humana Press Inc. and Totowa, New Jersey, USA, p. 457-509.

Subhedar, N. K. 2006. An update on neuropeptide Y in brain of vertebrates. Proc. Zool. Soc. Calcutta, 59: 71-86.

Sundstrom, L. F., Lohmus, M. and Devlin, R. H. 2016. Gene-environment interactions influence feeding and anti-predator behaviour in wild and transgenic coho salmon. Ecol. Appl., 26: 67-76.

Tian, J., He, G., Mai, K. and Liu, C. 2015. Effects of postprandial starvation on mRNA expression of endocrine, amino acid and peptide transporter, and metabolic enzyme-related genes in zebrafish (Danio rerio). Fish. Physiol. Biochem., 41: 773-787. DOI:10.1007/s10695-015-0045-x.

- Trinder, P. 1969a. Determination of blood glucose using an oxidase-peroxidase system with a non-carcinogenic chromogen. J. Clin. Pathol., 22: 158-161. doi: 10.1136/ jcp.22.2.158.

Trinder, P. 1969b. Enzymatic calorimetric determination of triglycerides by GOP-PAP method. Ann. Clin. Biochem., 6: 24-27. https://doi.org/10.1177/000456326900600108.

Wallace, R.A. and Selman, K. 1981. Cellular and dynamic aspects of oocyte growth in teleosts. Am. Zool., 21: 325-343.

Volkoff, H. 2016. The neuroendocrine regulation of food intake in fish: A review of current knowledge. Front. Neurosci., 10: 540 .

Walton, M. J. and Cowey, C. B. 1982. Aspects of intermediary metabolism in salmonid fish. Comp. Biochem. Physiol. B., 73: $59-79$.

Wu, S., Li, B., Lin, H. and Li, W. 2012. Stimulatory effects of neuropeptide $\mathrm{Y}$ on the growth of orange-spotted grouper (Epinephelus coioides). Gen. Comp. Endocrinol., 179: 159-166.

Yan, P., Jia, J., Yang, G., Wang, D., Sun, C. and Li, W. 2017. Duplication of neuropeptide $\mathrm{Y}$ and peptide $\mathrm{YY}$ in Nile tilapia Oreochromis niloticus and their roles in food intake regulation. Peptides, 88: 97-105. DOI:10.1016/j. peptides.2016.12.010.

Yokobori, E., Azuma, M., Nishiguchi, R., Kang, K. S., Kamijo, M., Uchiyama, M. and Matsuda, K. 2012. Neuropeptide $\mathrm{Y}$ stimulates food intake in the zebrafish, Danio rerio. J. Neuroendocrinol., 24: 766-773.

Zhou, Y., Liang, X. F., Yuan, X., Jie, L., He, Y., Fang, L., Guo, X., Liu, L., Li, B. and Shen, D. 2013. Neuropeptide Y stimulates food intake and regulates metabolism in grass carp, Ctenopharyngodon idellus. Aquaculture, 380: 52-61. 